\title{
Biomimetic chitosan-mediated synthesis in heterogeneous phase of bulk and mesoporous silica nanoparticles $\dagger$
}

\author{
Victoria Puchol, Jamal EI Haskouri,* Julio Latorre, Carmen Guillem, Aurelio Beltrán, \\ Daniel Beltrán and Pedro Amorós*
}

Received (in Cambridge, UK) 27th November 2008, Accepted 9th March 2009

First published as an Advance Article on the web 26th March 2009

DOI: $10.1039 / \mathbf{b 2 1 3 0 8 a}$

\begin{abstract}
Both bulk and mesoporous silica nanoparticles can be obtained in the form of granular aggregates using chitosan flakes as additive under very soft biomimetic reaction conditions.
\end{abstract}

Biomineralization, that is the formation under extremely soft conditions of complex hierarchical inorganic materials by biological systems, is an exciting research field of increasing interest. ${ }^{1}$ Indeed, while technological silica production usually requires vigorous conditions at high $\mathrm{pH}^{2}$ certain marine organisms and some higher plants are capable of forming silica skeletons under mild temperature and pressure conditions at circumneutral $\mathrm{pH} .^{1,3,4}$ Such in vivo processes generating intricate silica nano and macro-scale patterns are speciesspecific, presumably encoded in the genome $;^{5-7}$ the possibility of controlling them in the laboratory remains a long-term major challenge. Notwithstanding, there have been different biomolecules identified like silicatein, silaffin and polyamines, which can play key roles in the hydrolysis, condensation and aggregation of the silica species. ${ }^{3,4,8}$

Silica is widely used in industry, medicine and nanotechnology in a huge variety of forms..$^{2,7,9}$ This, coupled with the insufficiency of natural products of adequate purity and the scientific interest, justifies the search for bioinspired synthesis ${ }^{8,10}$ leading to new silica-based materials with simple hierarchical structures or, at least, allowing silica production under soft-conditions (low-cost strategies). Then, inspired by nature, a variety of reagents have been added to check in vitro silicification processes in solution. ${ }^{11,12}$ These additives, which intend to mimic the active natural molecules, can play different roles: catalysts, aggregation promoting reagents or structural directing agents. Otherwise, silicatein, silaffin and polyamines have been identified as constituents of the axial filaments in sponges and the cell walls in diatoms. ${ }^{3,8,9}$ Although this fact strongly suggests that they process silica in the heterogeneous phase, as far as we know, there is no information about in vitro processes carried out under this conditioning (i.e. on the role of solid phase additives).

Here we show how using solid flakes of chitosan (a commercial and low-cost biopolymer present in the shells of crustaceans and the cell walls of fungi and yeast, as well as in squid pens) $)^{13}$

Institut de Ciència dels Materials, Universitat de València,

P. O. Box 22085, 46071 Valencia, Spain.

E-mail:pedro.amoros@uv.es, haskouri@uv.es; Fax: +34 963543633; Tel: +34963543617

$\dagger$ Electronic supplementary information (ESI) available: Experimental details, adsorption-desorption isotherms and selected images. See DOI: $10.1039 / \mathrm{b} 821308 \mathrm{a}$ as additive, it is possible to promote silica polymerization and aggregation in the heterogeneous phase at room temperature, neutral $\mathrm{pH}$ and silica concentrations as low as those occurring in sea water or inside the diatom frustules. Our procedural approach leads to bulk biosilica nanoparticles or, alternatively, to similar mesoporous architectures when structural directing agents (SDA) are also added.

In order to mimic frustule conditions, ${ }^{6,14}$ we have performed the reactions in circulating silica solutions on chitosan flakes blocked in a part of the system in order to favour a certain confining effect (see ESI $\dagger$ ). Summarized in Table 1 are the main parameters concerning syntheses of some selected bulk and mesoporous samples. Experiments were carried out at $25{ }^{\circ} \mathrm{C}$ in circulating $\left(0.05 \mathrm{ml} / \mathrm{s} \mathrm{cm}^{2}\right)$ silica solutions. Syntheses in static conditions were also performed for comparative purposes. The circumneutral $\mathrm{pH}$ conditions were stabilized by using a buffer solution (Na-phosphate) or simulated sea water. ${ }^{15}$ TEOS was used as silica source with concentrations ranging from $0.001 \mathrm{M}$ to $0.1 \mathrm{M}$ (i.e. typical values inside the intracellular pools in diatoms before and after the deposition step). When compared to other previously described biomimetic syntheses, the amount of additive (chitosan) used here is small. ${ }^{11}$ Moreover, the proportion of active amine groups is extremely low because only those located at the flake surface (the estimated average ratio of surface/volume amine groups is $c a .3 .6 \times 10^{-7}$ ) could interact with silica species ("local or surface $\mathrm{pH}$ "). Some experiments assisted by the presence of surfactants as $\mathrm{SDA}^{16}$ have been performed in order to test the availability of mesoporous silicas under these biommimetic conditions. Blank experiments (without chitosan) were carried out for comparative purposes.

In the experiment performed in the absence of chitosan at neutral $\mathrm{pH}$, no solid formation was detected after long reaction times ( $c a .1$ week). Under these conditions, the hydrolysis of TEOS is extremely slow (with its minimum rate precisely at $\mathrm{pH}=7)^{2,17}$ On the contrary, when chitosan flakes are present in the reactor the hydrolysis of TEOS proceeds faster leading to silica nanoparticles through condensation reactions. In the presence of SDA species, when condensation is coupled with self-assembling through ionic $(\mathrm{CTABr})$ or van der Waals silica-surfactant micelle interactions (P123), mesoporous silica nanoparticles can be isolated.

After a certain reaction time, the starting transparent solutions become opaque as a consequence of silica particles aggregation. Under dynamic and static experiments, turbidity starts around the chitosan flakes and finally extends to the whole solution. In the presence of SDA additives, the turbidity 
Table 1 Selected synthetic and physical data for some bulk and mesoporous biosilicas

\begin{tabular}{|c|c|c|c|c|c|c|c|c|c|}
\hline Sample & & {$[\mathrm{Si}] / \mathrm{M}$} & $\begin{array}{l}\text { Chitosan }^{a} / \mathrm{N} / \\
\text { Si ratio }\end{array}$ & $\begin{array}{l}\text { CTABr or } \mathrm{P} 123 / \\
\mathrm{SDA} / \mathrm{Si} \text { ratio }\end{array}$ & Method $^{b}$ & Reaction medium & $\mathrm{pH}$ & $\begin{array}{l}\text { Reaction } \\
\text { time } / \mathrm{h}\end{array}$ & $\begin{array}{l}\text { Particle } \\
\text { size }^{c} / \mathrm{nm}\end{array}$ \\
\hline Blank & & 0.1 & & & & Na-Phosphate-1 M & 6.7 & 168 & \\
\hline 1 & Nanoparticles & 0.001 & $9 \times 10^{-6}$ & & D & Na-Phosphate-1 M & 6.7 & 120 & $110-140$ \\
\hline 2 & Nanoparticles & 0.001 & $5 \times 10^{-6}$ & & $\mathrm{D}$ & Simulated sea water- $0.5 \mathrm{M}$ & 7.8 & 120 & $60-80$ \\
\hline 3 & Nanoparticles & 0.1 & $4 \times 10^{-8}$ & & $\mathrm{~S}$ & Na-Phosphate-1 M & 6.7 & 120 & $30-40$ \\
\hline 4 & Nanoparticles & 0.1 & $4 \times 10^{-8}$ & & $\mathrm{~S}$ & Simulated sea water- $0.5 \mathrm{M}$ & 7.8 & 120 & $20-30$ \\
\hline 5 & MCM-41-like & 0.001 & $9 \times 10^{-6}$ & 0.26 CTABr: $\mathrm{Si}$ & $\mathrm{D}$ & Na-Phosphate-1 M & 6.7 & 96 & $130-170$ \\
\hline 6 & MCM-41-like & 0.1 & $4 \times 10^{-8}$ & $0.26 \mathrm{CTABr}: \mathrm{Si}$ & $\mathrm{S}$ & Na-Phosphate-1 M & 6.7 & 24 & $130-150$ \\
\hline 7 & MCM-41-like & 0.1 & $4 \times 10^{-8}$ & $0.26 \mathrm{CTABr}: \mathrm{Si}$ & $\mathrm{S}$ & Simulated sea water- $0.5 \mathrm{M}$ & 7.8 & 24 & $120-140$ \\
\hline 8 & SBA-16-like & 0.1 & $4 \times 10^{-8}$ & $0.01 \mathrm{P} 123: \mathrm{Si}$ & $\mathrm{S}$ & Simulated sea water- $0.5 \mathrm{M}$ & 7.8 & 48 & $100-180$ \\
\hline
\end{tabular}

${ }^{a}$ Estimated proportion of amine groups based on the chitosan flake weight and surface. ${ }^{b} \mathrm{D}=$ Dynamic; $\mathrm{S}=$ Static. ${ }^{c}$ Particle size range from SEM images.

increases much more rapidly, and especially when CTABr is used. This behaviour, which cannot be attributed to the chitosan activity, must be associated to the intrinsic character of the silica formation processes ${ }^{17}$ and also to the nature of the silica-SDA interaction (self-assembling through $\mathrm{N}^{0} \mathrm{I}^{0}$ van der Waals or an $\mathrm{S}^{+} \mathrm{I}^{-}$ionic mechanism).

Both the final (partially coated) chitosan flakes and the solid suspended in the solutions were studied by SEM. All the silicas synthesized in the presence of chitosan appear as materials with a granular texture. Shown in Fig. 1 are SEM images of bulk biosilicas synthesized by using an extremely low silica concentration $(1 \mathrm{mM})$ in $1 \mathrm{M} \mathrm{Na}$-phosphate buffer solution or simulated sea water reaction medium. In both cases, we obtain aggregates of irregular amorphous silica particles showing a certain proportion of textural-like porosity (see ESI $\dagger$ ). Differences observed among mean particle sizes are correlated with the buffer nature and concentration (see ESI $\dagger$ ).

The particle size differences become practically inexistent when CTABr is added (Fig. 2). The experiments give similar particle size distributions (centred at $c a .140 \mathrm{~nm}$ ) irrespective

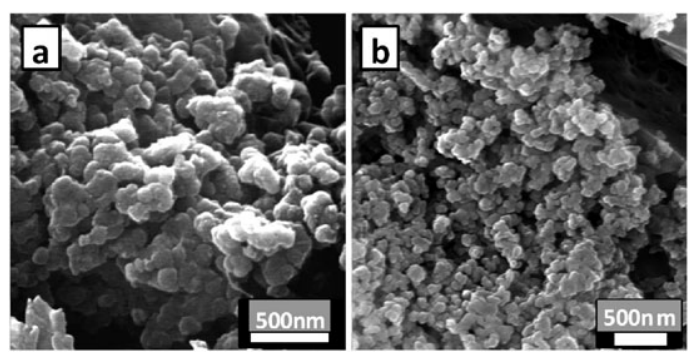

Fig. 1 Representative SEM images of bulk silica particles. (a) Sample 1. (b) Sample 2.

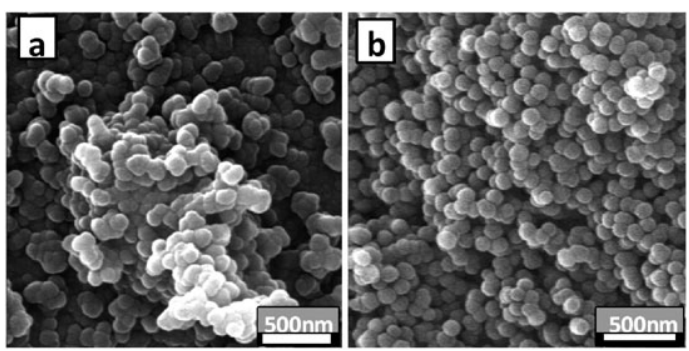

Fig. 2 Representative SEM images of mesoporous silica particles. (a) Sample 6. (b) Sample 7. of the reaction medium and TEOS concentration $(0.1 \mathrm{mM}-0.1 \mathrm{M})$ used. In these surfactant-assisted syntheses, while preserving the biomimetic conditions, the strong ionic interactions among silica oligomers and surfactant aggregates dominate the global process and limit the possible modulation of size or shape. Also the texture and morphology are preserved. The use of relatively concentrated $\mathrm{Si}$ solutions $(0.1 \mathrm{M})$ favours the precipitation of regular spherical particles after reaction times of only a few seconds, with a reasonable yield.

As confirmed by XRD and TEM (Fig. 3), we have actually synthesized (surfactant-assisted) MCM-41-like disordered silicas under biomimetic conditions. All materials synthesised by using CTABr display XRD patterns with a unique and strong diffraction peak in the low-angle domain, which is characteristic of disordered solids. TEM images also confirm the regular and spherical morphology observed by SEM bringing out an architecture based on aggregates of spherical mesoporous particles describing large inter-particle voids.

The porosity is further illustrated by the $\mathrm{N}_{2}$ adsorptiondesorption isotherms (Fig. 4). As can be noted, the curves show two well-defined adsorption steps associated to the intraand inter-nanoparticle mesopores. The resulting silica display high BET surface areas ( $c a .566 \mathrm{~m}^{2} / \mathrm{g}$ ) and conventional narrow pore size $(\mathrm{BJH})$ distributions centred at $c a .2 .9 \mathrm{~nm}$. Nevertheless a significant increase of pore wall thickness $\left(a_{0}-\mathrm{BJH}\right)$ of $c a .4 .6 \mathrm{~nm}$ is achieved, when compared to MCM-41 (1.6-1.8 nm). At circumneutral $\mathrm{pH}$ values there is an extremely low proportion of charged silicon species in solution. $^{2}$ Then, a large polymerization degree (originating from thicker walls) seems to be necessary to achieve the minimum negative charge density at the surface to interact

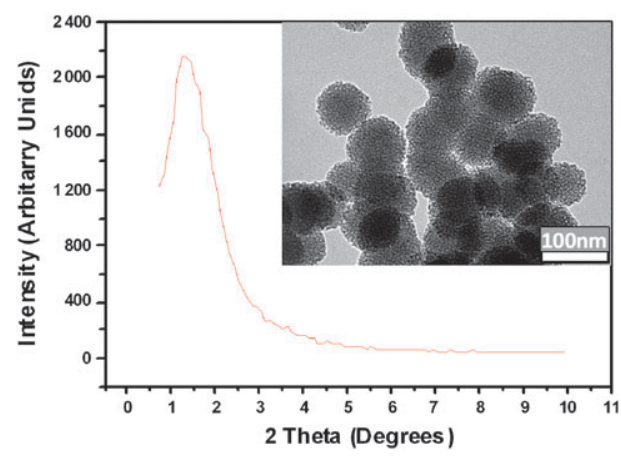

Fig. 3 XRD pattern and TEM image of Sample 7. 


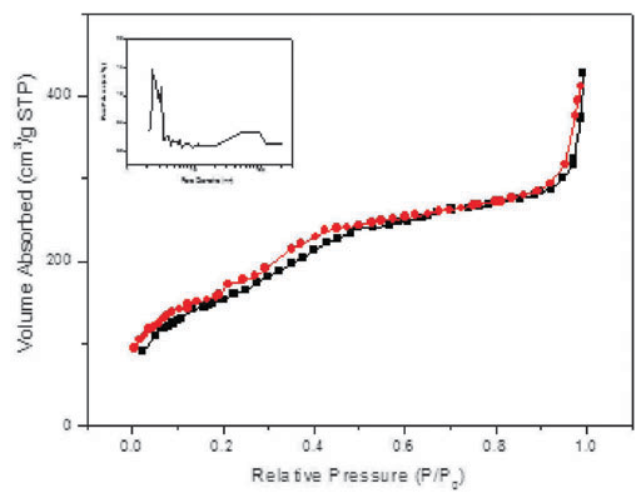

Fig. $4 \mathrm{~N}_{2}$ adsorption desorption isotherms of Sample 7.

with surfactant entities. ${ }^{18}$ This feature warrants better thermal, hydrothermal and mechanic stability. Under the extremely low $\mathrm{CTABr}$ concentration used (far from $\mathrm{cmc}$ ), isolated molecules or small surfactant aggregates are expected. The lack of balance between the sizes of inorganic and organic counterparts favours the isolation of disordered materials.

Total loss of order and a low porosity characterize silica obtained when pluronic block copolymers (P123) were used as SDA. A higher variation in particle size was observed when compared to MCM-41-like biosilicas (see TEM in ESI $\dagger$ ). The shape of the $\mathrm{N}_{2}$ adsorption-desorption isotherms (see $\mathrm{ESI} \dagger$ ), with a large hysteresis phenomena, indicates the existence of open cage-like mesopores besides a significant proportion of voids corresponding to closed pores. These features suggest that, under the biomimetic conditions used, the porosity achieved through the use of P123 as SDA must be viewed as originating from micelle entrapment during the silica growing instead of a true self-assembling process. The extremely weak $\mathrm{N}^{0} \mathrm{I}^{0}$ interaction between large silica oligomers and P123 aggregates must be responsible for the low porosity and low degree of order achieved.

The chitosan lacks a structure directing effect, but obviously promotes silica growth in biomimetic conditions. Terminal amine groups on the chitosan surface seem to play a bi-functional role, promoting both the silica hydrolysis/condensation and the subsequent aggregation processes. In fact, the chitosan terminal amines could catalyze TEOS hydrolysis through an SN2 mechanism. Silica monomers (or small oligomers) can be adsorbed on to the protonated amino groups, and the subsequent polymerization and particle growing become possible because of the proximity among charged amine groups (see ESI $\dagger$ ), without prejudicing further polymerization in solution. Then, the relatively high amine availability at the chitosan surface, which can be thought of as a "high local $\mathrm{pH}$ ", constitutes the key factor in the present biomimetic strategy. In fact, a significant drop in silica formation efficiency is observed when similar amine concentrations in the form of soluble amines (ammonia or alkylamines) were used. The use of ammonia leads to a low silica formation after $c a$. one weak. When alkylamines were used, silica precipitation occurs after 1-2 days. Probably, the tendency of alkylamines to associate in the form of (pre)micellar entities favours a certain amine local concentration enough to increase the silica aggregation when compared to ammonia.

Once the possible role of chitosan under biomimetic conditions is understood, we can develop a bioinspired strategy for synthesizing silica-based materials under soft conditions. Thus, in order to achieve high reaction yields and short reaction times, we can increase both the TEOS concentration (0.5-1 M) and the chitosan amount $(\times 100)$. Under these modified conditions, turbidity and subsequent precipitation occurs after reaction times ranging from a few seconds (MCM-41-like silicas) to some hours (amorphous silicas). In contrast to previously described biomimetic/bioinspired syntheses, the fact that the additive works in the heterogeneous (solid) phase results in amine-free final solids, which actually can be considered as pure silica materials. Moreover, this solid additive can be easily removed by filtration and reused.

In short, we describe for the first time the use in the heterogeneous phase of an additive able to promote silica formation and aggregation in the form of bulk or mesoporous particles working under extremely soft conditions mimicking the in vivo processes occurring in diatoms.

We thank the MEC (CTQ2006-15456-C04-03/BQU) and the Generalitat Valenciana for financial support. JEH thanks MEC for a Ramón \& Cajal contract.

\section{Notes and references}

1 S. Mann, Biomineralization. Principles and Concepts in Bioinorganic Materials Chemistry, Oxford University Press Inc., New York, 2001.

2 R. K. Iler, The Chemistry of Silica, John Wiley \& Sons, New York, 1979; C. C. Perry, Rev. Mineral. Geochem., 2003, 54, 291.

3 M. Sumper and E. Brunner, Adv. Funct. Mater., 2005, $16,17$.

4 H. C. Schröder, X. Wang, W. Tremel, H. Ushijima and W. E. G. Muller, Nat. Prod. Rep., 2008, 25, 455.

5 Silicon and Siliceous Structures in Biological Systems, ed. T. L. Simpson and B. E. Volcani, Springer, New York, 1981; F. E. Round, R. M. Crawford and D. G. Mann, The Diatoms: Biology \& Morphology of the Genera, Cambridge University Press, New York, 2003.

6 M. Hildebran, Chem. Rev., 2008, 108, 4855.

7 T. Coradin and J. Livage, Acc. Chem. Res., 2007, 40, 819.

8 R. L. Brutchey and D. E. Morse, Chem. Rev., 2008, 108, 4915.

9 H. C. Schröder, D. Brandt, U. Schlobmacher, X. Wang, M. N. Tahir, W. Tremel, S. I. Belikov and W. E. G. Muller, Naturwissenschaften, 2007, 94, 339.

10 C. Sanchez, H. Arribart and M. M. G. Guille, Nat. Mater., 2005, 4, 277.

11 S. V. Patwardhan, S. J. Clarson and C. C. Perry, Chem. Commun., 2005, 1113, and references therein.

12 A. Corma, M. J. Díaz-Cabañas, M. Moliner and G. Rodríguez, Chem. Commun., 2006, 3137.

13 G. F. Payne and S. R. Raghavan, Soft Matter, 2007, 3, 521.

14 M. Hildebrand, Biomineralization, ed. E. Baüerlein, Wiley-VCH, New York, 2004, p. 159.

15 M. Kosmulski, E. Maczka, K. Marczewska-Boczkowska and J. B. Rosenholm, Mar. Pollut. Bull., 2003, 46, 120.

16 C. T. Kresge, M. E. Leonowicz, W. J. Roth, J. C. Vartuli and J. S. Beck, Nature, 1992, 359, 710.

17 R. Aelion, A. Loebel and F. Eirich, J. Am. Chem. Soc., 1950, 72, 5705.

18 J. El Haskouri, J. M. Morales, D. Ortiz de Zarate, L. Fernández, J. Latorre, C. Guillem, A. Beltrán, D. Beltrán and P. Amorós, Inorg. Chem., 2008, 47, 8267. 